\title{
Investigating IT Effectiveness: Perspectives Relative to Cultural Differentiation Between IT Users and Service Providers
}

\author{
Richmond Adebiaye \\ Department of Cybersecurity Technology, University of Maryland University College (UMUC), Adelphi, USA
}

Email address:

Richmondwiz@yahoo.com

To cite this article:

Richmond Adebiaye. Investigating IT Effectiveness: Perspectives Relative to Cultural Differentiation Between IT Users and Service Providers. American Journal of Networks and Communications. Vol. 6, No. 3, 2017, pp. 54-61. doi: 10.11648/j.ajnc.20170603.11

Received: March 26, 2017; Accepted: April 14, 2017; Published: May 17, 2017

\begin{abstract}
The inherent relationship between business and Information Technology creates two simultaneous constituencies of diverse organization architectures with correspondingly valued models. However, the widening chasm between information technology (IT) groups and their business Professionals produces perceptual and cultural gaps between the users and providers of IT services. Several studies have used inductive reasoning to investigate corporate culture, organizational architecture, and IT effectiveness to determine the best framework for mitigating these different perceptual and cultural gaps. Using technological self-efficacy theory, this study tests and analyzes the perceptual and cultural silos in the relationship between modern business and information technology services. The research provides empirical evidence that supports the research hypothesis that there exists the aforementioned chasm between business and IT services, leading to different approaches for delivering IT service in various business organizations. This chasm holds true of the silo effects for all firms regardless of the strategic intents of businesses and information technology. The study also shows a positive relationship between business and IT professionals with differential perceptions and cultural gaps. This relationship illustrates how business professionals rely on "trusted IT partners while IT professionals argue for a valued organizational model with high standards of efficiency and reliability". The study ultimately provides a framework for measuring the perceived effectiveness of IT within business architecture and the alignment between providers of IT services and the strategic goals of a modern business.
\end{abstract}

Keywords: Business, Technology Services, Information Technology, Cultural Gaps, IT Effectiveness

\section{Introduction}

The increasing differences between Information Technology (IT) experts and their business Professionals have produced perceptual and cultural gaps between the IT service users and the IT services providers. The perceptual gaps include perceptions of IT effectiveness, organizational attributes, creativity in work and many others while the cultural gaps include corporate culture, communication, and motivational attributes. This study, therefore, seeks to investigate IT effectiveness by examining how the widening chasm between IT experts and business groups has generated gaps in perceptual and cultural aspects among the IT users and IT providers, resulting in complex partnerships among the IT stakeholders.

Research Specific Objectives
To address the above research problem, the study came up with research objectives, research questions, and some research hypotheses. The research objectives are:

(a) To determine existing differences/gaps between the IT providers/experts and their business professionals (IT users).

(b) To investigate how corporate cultural framework mitigates the perceptual and cultural differences between the IT service users and providers.

(c) To establish how IT providers and their business professionals' plan organizational architecture ameliorate the perceptual and cultural differences between them.

(d) To determine how an IT effectiveness framework will help in the reduction of perceptual and cultural differences between the IT service users and providers. 


\section{Related Work}

Several literatures include perceptual and cultural problems in the role technology plays in all aspects of human endeavors. Jiang et al analyzed the importance of a good relationship between "business professionals and IT professionals for organizational success but also acknowledges that there is a lack of research on the differences of perception between the two constituencies and the subsequent effects of these differences on IT effectiveness and organizational success" [1]. Even at this analysis, there are still requirements needed for change and progress which ultimately places technology and the implementers of technology in an "unenviable" position. McAdams explained how business professionals and IT professionals think and behave differently in many important ways [2]. Volti also indicated that "Information technology professionals, especially software engineers, have in the past had an aptitude for numbers, theorems, materials, and spatial relationships, while business managers have preferred to focus on people, politics, and financial matters [3]. Cooper also justified this by indicating that "IT professionals used control over simplicity, understanding over success, possibilities over probability, and frequently adopt a work style that is marked by isolation, pressure, and long and odd hours" [4]. The researcher concluded the arrogance and superior attitudes portrayed by IT professionals against business professionals which often resort to bullying tactics when challenged by business professionals. The conclusion by Henderson was the dysfunctional working relationships have hampered business results, as reflected in financial returns and market share, and led to overly complex technology infrastructures [5].

\subsection{Research Questions}

The following research questions were set to enable the researcher to achieve the corresponding research objectives. They are mainly derived from the research problem.

(a) What are the differences between IT providers and their business professionals which results in different approaches for delivering IT service?

(b) How does corporate culture mitigate the perceptual and cultural differences between the IT service users and providers?

(c) How will IT professionals and their business counterparts' organizational architecture ameliorate the perceptual and cultural differences between the IT service users and providers?

(d) How will an IT effectiveness framework help in the reduction of the perceptual and cultural differences between the IT service users and providers?

\subsection{Research Hypotheses}

To significantly answer the above research questions, the following research hypotheses were set. They are derived from the above research questions and are:

\subsubsection{Research Question 1}

H0: There are no differences between IT professionals/experts and their business professionals which result into different approaches in delivering IT services.

H1: There are differences between IT professionals/experts and their business professionals which result in different approaches for delivering IT services.

\subsubsection{Research Question 2}

$\mathrm{H} 0$ : There is no corporate culture framework that mitigates the perceptual and cultural differences between the IT service users and providers.

H1: There is corporate culture framework to mitigate the perceptual and cultural differences between the IT service users and providers.

\subsubsection{Research Question 3}

H0: There is no organizational architecture to ameliorate the perceptual and cultural differences between the IT service users and providers.

H1: There is organizational architecture to ameliorate the perceptual and cultural differences between the IT service users and providers.

\subsubsection{Research Question 4}

H0: There is no correlation between an IT effectiveness and perceptual and cultural gaps between the IT service users and providers.

H1: There is correlation between an IT effectiveness and perceptual and cultural gaps between the IT service users and providers.

\section{Methods}

\subsection{The Study Variable}

The Dependent Variable (DV) is IT effectiveness relative to cultural differentiation between IT users and providers while the Independent Variables (IVs) are: Perceptions of IT professionals and their business counterparts, corporate culture between the two, and organizational architecture of IT professionals and business on IT effectiveness relative to cultural differentiation between IT users and providers.

The Confounding Variables (CVs) include demographic factors, such as age, professional experience, gender, level of education and socioeconomic status.

\subsection{Sample Size and Sampling Procedure}

The research targeted all IT stakeholders including IT users and IT providers in business technology organizations. Due to the large concentration of IT users and IT providers in technology field, a sample size of 200 was deemed adequate for this research. Kothari suggests that a sample size of 100 to 200 participants is appropriate for a quantitative survey research design to achieve the research objectives and make the necessary generalizations about the studied population, whether such generalizations are analytical or logical in nature [6]. 
Simple random sampling was used to select the 200 participants for the study. Researchers often obtain a representative sample by using random sampling, which will result in saving time and resources while allowing for accurate inferences about the research questions [7]. From the sample size of 200 IT users and IT providers who received online questionnaires, only 168 respondents completed and returned the questionnaires. The 168 IT professionals and service users represented $84 \%$ response rate.

\subsection{Data Collection}

A survey-style design was selected for this particular research as it sought to gain insights concerning phenomena in the area of IT effectiveness as related to cultural differences between IT users and providers. This survey design was also found reliable in providing information for valid generalizations.

Data was obtained by online questionnaires. The online questionnaires were developed to ascertain data that would generate valid and reliable information about the population under study. The online questionnaires were structured in two sections: Personal demographic data and data concerning the research-specific objectives. The questionnaires were checked for feasibility, validity, and reliability by use of test and pretest methods, as well as piloting and revising methods with a 5-point Likert scale of choices.

\subsection{Data Analysis Procedure}

The data concerning the research questions were analyzed using correlations, t-tests to ascertain what gaps between IT experts and their business Professionals and for differences between IT service users and providers. Analysis of Variance
(ANOVA) tests and multiple regressions were tested on the research questions. The correlation coefficients ( $\mathrm{r}$ ), the beta values $(\beta)$, and their respective $p$-values were used to evaluate the research hypothesis derived from the research questions. The results of this data analysis were interpreted to derive the results of this study.

The data analysis was mainly anchored on technological self-efficacy theory in which the perceptual and cultural silos within the relationship between modern business and information technology service professionals were tested and analyzed. Apart from this, analysis also examined the gaps/division (chasm) between business and IT service professionals, which led to different approaches for delivering IT services in organizations.

\section{Results}

\subsection{Reliability, Bias and Validity Tests}

The analysis showing reliability, bias, and validity of the data was accomplished using the Cronbach's test. Table 1 below shows the Cronbach's reliability and validity tests in the three dimensions: dependent variable (IT service effectiveness), independent variables (IT experts and business groups perceptual and cultural aspects), and confounding variables (demographic factors).

The results show that Cronbach's alpha for IT service effectiveness (DV) was 0.950 with a sample of 168 respondents, for perceptual and cultural aspects (IVs), Cronbach's alpha was 0.803 with same sample size and the demographic factors (CVs) had Cronbach's alpha of 0.783 . Since Cronbach's alpha was more than 0.7 , this proves that the survey data was reliable and valid [8].

Table 1. Reliability and Validity Statistical Test.

\begin{tabular}{llllllll}
\hline IT service effectiveness (DV) & \multicolumn{2}{l}{ perceptual and cultural aspects (IVs) } & \multicolumn{2}{c}{ demographic factors(CVs) } \\
\hline $\begin{array}{llllll}\text { Cronbach's } \\
\text { Alpha }\end{array}$ & $\begin{array}{l}\text { N of } \\
\text { Items }\end{array}$ & $\begin{array}{l}\text { N of } \\
\text { Variables }\end{array}$ & $\begin{array}{l}\text { Cronbach's } \\
\text { Alpha }\end{array}$ & \multirow{2}{*}{ N of Items } & \multirow{2}{*}{ N of Variables } & $\begin{array}{l}\text { Cronbach's } \\
\text { Alpha }\end{array}$ & $\begin{array}{l}\text { N of Items } \\
\text { Variables }\end{array}$ \\
\hline 0.950 & 168 & 1 & 0.803 & 168 & 16 & 0.783 \\
\hline
\end{tabular}

\subsection{Demographic Data Analysis}

According to Table 2, 58.9\% respondents were males and $41.1 \%$ were females. This indicates lack of gender parity amongst respondents. Concerning the age of respondents, Table 2 shows that $36.9 \%$ of the respondents were aged 31 40 years, $32.7 \%$ were $21-30$ years old, $19.6 \%$ were less than 20 years old and the minority group was $41-50$ years with $7.1 \%$. The distribution of age shows that most of the respondents were aged 31-40 years. The work experience is represented in the bar graph of figure 1.

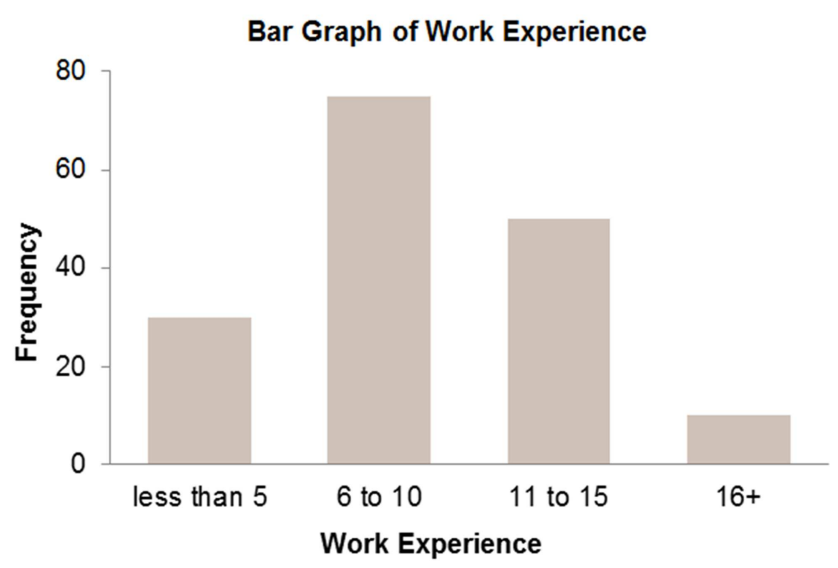

Figure 1. Work Distribution. 
experience of the respondents: 6-10 years' experience represent $(44.6 \%)$ followed by those having a professional experience of $11-15$ years $(29.8 \%)$.

The minority group was that of individuals with less than 5 years $(17.9 \%)$ of experience. The respondents were also asked about their highest level of education. Table 2 shows that $43.5 \%$ of the respondents had an Associate degree, $30.3 \%$ had a Undergraduate University degree, and $26.2 \%$ had a high school level of education. On testing the socioeconomic background of respondents, results indicate $60.1 \%$ of respondents consider themselves middle-income level group, while $39.9 \%$ considers themselves as upper middle income level. As shown in the pie chart of Figure 2.

Table 2. Frequency distribution of demographic data.

\begin{tabular}{|c|c|c|c|c|}
\hline Variable & Attribute & Frequency & Percent & $\begin{array}{l}\text { Cumulative } \\
\text { Percent }\end{array}$ \\
\hline \multirow[t]{2}{*}{ Gender } & Male & 99 & 58.9 & 59.9 \\
\hline & Female & 69 & 41.1 & 100 \\
\hline \multirow[t]{5}{*}{ Age (years) } & $<20$ & 33 & 19.6 & 19.6 \\
\hline & $21-30$ & 55 & 32.7 & 52.4 \\
\hline & $31-40$ & 62 & 36.9 & 89.3 \\
\hline & $41-50$ & 12 & 7.1 & 96.4 \\
\hline & $50+$ & 6 & 3.6 & 100 \\
\hline \multirow[t]{4}{*}{ Education } & High School & 44 & 26.2 & 26.2 \\
\hline & Diploma & 73 & 43.5 & 69.7 \\
\hline & University & 51 & 30.3 & \\
\hline & Total & 112 & 100 & \\
\hline \multirow[t]{5}{*}{ Work Experience } & $<5$ & 30 & 17.9 & 17.9 \\
\hline & $6-10$ & 75 & 44.6 & \\
\hline & $11-15$ & 50 & 29.8 & \\
\hline & $16+$ & 13 & 7.7 & \\
\hline & Total & 168 & 100 & \\
\hline \multirow[t]{4}{*}{ Ethnic Groups } & Asians & 96 & 57.1 & 57.1 \\
\hline & Arabs & 45 & 26.8 & 83.9 \\
\hline & Expatriates & 27 & 16.1 & 100 \\
\hline & Total & 168 & 100 & \\
\hline \multirow[t]{3}{*}{$\begin{array}{l}\text { Socioeconomic } \\
\text { level }\end{array}$} & Low & 101 & 60.1 & 60.1 \\
\hline & High & 67 & 39.9 & 100 \\
\hline & Total & 168 & 100 & \\
\hline
\end{tabular}

\subsection{The Silos Between IT Experts (IT Providers) and Business Groups (IT Service Users) Which Resulted in Different Approaches in Delivering IT Service}

The cultural gaps or differences between IT providers and IT service users in terms of delivery of IT service were analyzed using mean differences and t-tests. The two tests were used to determine the mean differences between the two groups in terms of the independent variables of the study and whether these mean differences represented significant results.

\section{Socio-Economic Index}

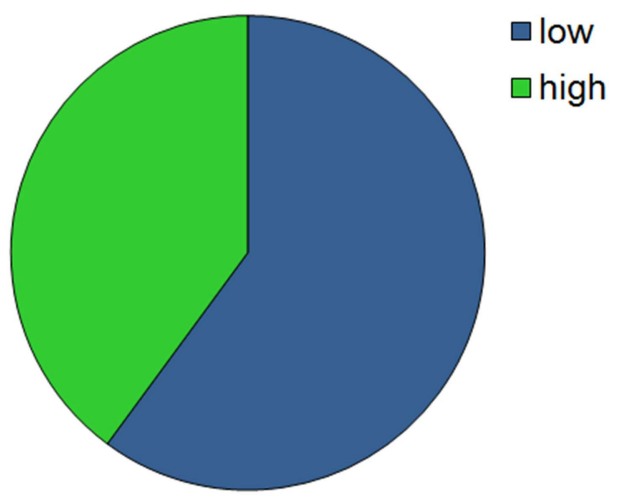

Figure 2. Pie chart showing socio-economic status distribution.

Table 3 below shows differences between IT providers and IT service users in respect to perceptions of IT effectiveness. The results indicate that IT providers have higher mean perception $(\mu=4.20)$ than IT users $(\mu=3.49)$. Similarly, in terms of organizational acceptability known as" corporate culture of IT experts" and their business Professionals, IT providers have a higher mean $(\mu=4.00)$ compared to IT service (Business Professionals) users $(\mu=2.97)$. In organizational architecture's influence on IT effectiveness relative to cultural differentiation, IT users have a higher mean $(\mu=4.50)$ than IT users $(\mu=3.99)$. Lastly, concerning overall IT effectiveness relative to cultural differentiation, IT providers have a higher mean $(\mu=4.33)$ than IT service users $(\mu=3.65)$. Therefore, it can be concluded that IT effectiveness relative to cultural differentiation shows cultural gaps between IT providers and users. This assertion can be investigated further by tests of hypothesis.

Table 3. Mean differences between IT Providers and IT users.

\begin{tabular}{lllll}
\hline Variable & Group & N & Mean & $\begin{array}{l}\text { Std. } \\
\text { Deviation }\end{array}$ \\
\hline $\begin{array}{l}\text { perceptions of IT } \\
\text { effectiveness }\end{array}$ & IT Expert & 97 & 4.20 & 0.010 \\
$\begin{array}{llll}\text { corporate culture } \\
\text { on IT }\end{array}$ & IT Expert & 97 & 4.00 & 0.010 \\
& Business Group & 70 & 2.97 & 0.239 \\
organizational & IT Expert & 97 & 4.50 & 0.008 \\
architecture on IT & Business Group & 70 & 3.99 & 0.120 \\
& IT Expert & 97 & 4.33 & 0.242 \\
IT effectiveness & Business Group & 70 & 3.65 & 0.120 \\
\hline
\end{tabular}

Table 4 shows the mean difference of perceptions of IT effectiveness between the IT providers and IT users is 0.710 . This mean difference is significant since the $\mathrm{p}$-value is less than $0.05 \quad(t=1.979$ and $p=0.014)$. Similarly, the mean difference in corporate culture on IT effectiveness between the IT providers and IT service users is 1.029. This mean difference is statistically significant $(\mathrm{t}=2.179$ and $\mathrm{p}$ value $=0.008$ ). Regarding organizational cultural influence on IT effectiveness, the difference between the IT providers and IT service users is significant with a mean difference of 0.511 
and $\mathrm{t}=2.179$ and $\mathrm{p}=0.034$. The overall mean difference of perception of IT effectiveness is 0.681 , where $t=1.715$ and $\mathrm{p}=0.026$.

Table 4. T-test for mean difference in IT providers and users.

\begin{tabular}{|c|c|c|c|c|}
\hline Variable & Mean Difference & $\mathbf{T}$ & df & p \\
\hline $\begin{array}{l}\text { Perceptions of IT } \\
\text { effectiveness }\end{array}$ & 0.710 & 1.979 & 165 & 0.014 \\
\hline Corporate culture on IT & 1.029 & 2.179 & 165 & 0.008 \\
\hline $\begin{array}{l}\text { Organizational } \\
\text { architecture on IT }\end{array}$ & 0.511 & 1.369 & 165 & 0.034 \\
\hline IT effectiveness & 0.681 & 1.715 & 165 & 0.026 \\
\hline
\end{tabular}

Table 5 below shows the correlation between corporate culture and IT effectiveness was 0.586 . This indicates a moderate positive correlation between the corporate culture and IT effectiveness. Therefore, corporate culture has a mitigation influence on IT effectiveness.

Table 5. Correlations between IT effectiveness and corporate culture.

\begin{tabular}{llll}
\hline Variable & $\begin{array}{l}\text { Mean } \\
\text { Difference }\end{array}$ & $\begin{array}{l}\text { IT } \\
\text { effectiveness }\end{array}$ & $\begin{array}{l}\text { Corporate } \\
\text { Culture on IT }\end{array}$ \\
\hline IT effectiveness & Correlation & 1 & 0.586 \\
& $\mathrm{p}$ & & $<0.001$ \\
& $\mathrm{n}$ & 168 & 168 \\
Corporate culture on IT & Correlation & 0.586 & 1 \\
& $\mathrm{p}$ & $<0.001$ & \\
& $\mathrm{n}$ & 168 & 168 \\
\hline
\end{tabular}

The Null Hypothesis: corporate culture framework cannot mitigate the perceptual and cultural differences between the IT service users and the providers of IT services.

The ANOVA results show that the corporate culture framework influences the perceptual and cultural differences between the IT service users and the providers $(\mathrm{F}=21.541$ and $\mathrm{p}<0.001)$. As the $\mathrm{p}$-value is less than 0.05 , then the null hypothesis is rejected and we conclude that the corporate culture framework can significantly mitigate the perceptual and cultural differences between the IT users and IT the providers.

\subsection{The Mitigating Factor Effects on IT Effectiveness Between the IT Users and the IT Providers in Terms of Corporate Culture}

ANOVA tests of the effect of corporate culture on IT effectiveness are represented in the Table 6 below which shows a significant mean square of 0.517 for $\mathrm{p}<0.001$.

Table 6. ANOVA Tests of the Effect of Corporate Culture on IT Effectiveness.

\begin{tabular}{llllll}
\hline & Sum of Squares & df & Mean Square & F & p \\
\hline $\begin{array}{l}\text { Between } \\
\text { Groups }\end{array}$ & 1.033 & 2 & 0.517 & 21.541 & $<0.001$ \\
$\begin{array}{l}\text { Within } \\
\text { Groups }\end{array}$ & 3.943 & 165 & 0.024 & & \\
Total & 4.976 & 167 & & & \\
\hline
\end{tabular}

\subsection{How Organizational Architecture Will Ameliorate the Perceptual and Cultural Differences Between the IT Users and IT the Providers}

Results in Table 7 below show that the correlation between organizational architecture and IT effectiveness was 0.728 . This indicates a strong positive correlation between the organizational architecture and IT effectiveness. Therefore, organizational architecture can ameliorate IT effectiveness.

Table 7. Correlation between IT Effectiveness \& Corporate Culture frameworks.

\begin{tabular}{llll}
\hline Variable & $\begin{array}{l}\text { Mean } \\
\text { Difference }\end{array}$ & $\begin{array}{l}\text { IT } \\
\text { effectiveness }\end{array}$ & $\begin{array}{l}\text { corporate } \\
\text { culture on IT }\end{array}$ \\
\hline IT effectiveness & Correlation & 1 & 0.728 \\
& $\mathrm{p}$ (2-tailed) & & $<0.001$ \\
& $\mathrm{n}$ & 168 & 168 \\
$\begin{array}{l}\text { Organizational } \\
\text { architecture }\end{array}$ & Correlation & 0.728 & 1 \\
& $\mathrm{p}$ (2-tailed) & $<0.001$ & \\
& $\mathrm{n}$ & 168 & 168 \\
\hline
\end{tabular}

The ANCOVA results in Table 8 show that both the organizational architecture framework and the IT group influence the perceptual and cultural differences in the IT industry. The IT groups have significant moderating influence on organizational architecture concerning IT effectiveness $(\mathrm{F}=13.782$ and $\mathrm{p}<0.001)$. It is also worth noting that organizational architecture alone has influences on the perceptual and cultural differences of IT effectiveness $(\mathrm{F}=55.128$ and $\mathrm{p}<0.001)$. Therefore, organizational architecture can ameliorate the perceptual and cultural differences between the IT service users and the IT providers.

Table 8. ANCOVA Tests for Effects of Organizational Architecture on IT Effectiveness.

\begin{tabular}{llllll}
\hline Source & $\begin{array}{l}\text { Type III Sum } \\
\text { of Squares }\end{array}$ & df & $\begin{array}{l}\text { Mean } \\
\text { Square }\end{array}$ & F & p \\
\hline Regression & 4.300 & 1 & 4.300 & 55.128 & $<0.001$ \\
$\begin{array}{l}\text { IT Group } \\
\text { organizational } \\
\text { architecture }\end{array}$ & 12.986 & 165 & 0.078 & 13.782 & $<0.001$ \\
\hline
\end{tabular}

\subsection{IT Effectiveness Framework on Reduction of the Perceptual and Cultural Differences Between the IT Users and the IT Providers}

The ANCOVA results in Table 9 below show that all the independent variables except perceptions on IT effectiveness have significant influences on the perceptual and cultural differences in the IT industry. The IT groups have significant moderating influence on IT effectiveness $(\mathrm{F}=24.493$ and $\mathrm{p}<0.001)$. Organizational architecture framework has an influence on the perceptual and cultural differences of IT effectiveness $(\mathrm{F}=204.743$ and $\mathrm{p}<0.001)$. Corporate culture has an influence on the perceptual and cultural differences of IT effectiveness $(\mathrm{F}=347.173$ and $\mathrm{p}<0.001)$. While perceptions of IT effectiveness on itself has no influence $(\mathrm{F}=1.017$ and $\mathrm{p}=0.362)$. Therefore, IT groups, organizational architecture, and corporate culture can ameliorate the perceptual and cultural differences between the IT service users and the IT providers. 
Table 9. ANCOVA Tests for Effects of IT effectiveness Framework on the Perceptual and Cultural differences of IT Services.

\begin{tabular}{llllll}
\hline Source & $\begin{array}{l}\text { Type III Sum } \\
\text { of Squares }\end{array}$ & df & $\begin{array}{l}\text { Mean } \\
\text { Square }\end{array}$ & F & p \\
\hline Regression & 3.644 & 1 & 3.644 & 15.970 & $<0.001$ \\
$\begin{array}{l}\text { IT Group } \\
\text { organizational } \\
\text { architecture }\end{array}$ & 0.652 & 1 & 0.652 & 24.493 & $<0.001$ \\
$\begin{array}{l}\text { corporate culture } \\
\text { on IT }\end{array}$ & 0.312 & 165 & 0.078 & 204.743 & $<0.001$ \\
$\begin{array}{l}\text { perceptions of IT } \\
\text { effectiveness }\end{array}$ & 2639.0 & 168 & 15.708 & 1.017 & 0.362 \\
Error & 6.614 & 164 & 0.040 & & \\
\hline
\end{tabular}

\subsection{Multiple Regression Model of IT Effectiveness}

The IT effectiveness and its influence on perceptual and cultural differences of IT service users and the IT providers, depending on both demographic and independent variables (IT groups, organizational architecture, corporate culture, and perceptions of IT effectiveness), will be analyzed using a multiple regression model. In this analysis, we tested whether the model is statistically significant enough to infer a relationship, whether the model is significant in its test, and whether all the independent and confounding variables are significant in explaining the IT effectiveness on organizational operational systems.

The results show there is significant correlation between IT effectiveness and the demographic and independent variables when modeled together $(\mathrm{r}=0.813)$. The results also indicate that the model is statistically significant enough to explain the variability of IT effectiveness based on the demographic and independent variables of the study. The strength of this model is about $66.1 \%$ (R-squared $=0.661$ ).

The ANOVA test in Table 10 below shows that the model is significant in describing and predicting the IT effectiveness using both demographic factors and independent variables $(\mathrm{F}=2.922$ and $\mathrm{p}=0.010)$.
Table 10. Model's ANOVA Test.

\begin{tabular}{llllll}
\hline & Sum of Squares & df & Mean Square & F & p \\
\hline Regression & 0.659 & 6 & 0.110 & 2.922 & $0.010^{\mathrm{b}}$ \\
Residual & 6.050 & 161 & 0.038 & & \\
Total & 6.708 & 167 & & & \\
\hline
\end{tabular}

a. Dependent Variable: IT Effectiveness

b. Predictors: (Constant), Demographic \& Independent variables

Table 11 shows socio-economic status $(\beta=0.560$ and $\mathrm{p}=0.013)$, age $(\beta=1.049$ and $\mathrm{p}=0.002)$, level of education $(\beta=0.641$ and $\mathrm{p}=0.001)$, organizational architecture $(\beta=1.210$ and $\mathrm{p}=0.000)$, and corporate culture $(\beta=0.889 \& \mathrm{p}$ value $=0.000$ ) can be modeled to create a significant description of IT effectiveness as every p-value is less than 0.05 . The results also indicate that when the socioeconomic status with $(\beta=0.560)$ of an IT stakeholder increases by one, the IT effectiveness will increase by 0.560 . Similarly, when age $(\beta=1.049)$ of increases by one, the IT effectiveness will increase by 1.049. Finally, when the level of education $(\beta=0.641)$ of an IT user and provider increases by one, the IT effectiveness will increase by 0.641 . The results also show that when organizational architecture $(\beta=1.210)$ of IT industry increases by one, the IT effectiveness will increase by 1.210 . Additionally, when corporate culture $(\beta=0.889)$ of an IT industry improves by one, the IT effectiveness will increase by 0.889 .

Where:

ITE is IT Effectiveness

SES is Socio-Economic Status

Age is Age Factor

EL is Education Level

$\mathrm{OA}$ is Organizational Architecture

$\mathrm{CC}$ is Corporate Culture

$\mathrm{c}$ is the constant

Table 11. The Data Analysis Summary.

\begin{tabular}{|c|c|}
\hline Research Question & Result \\
\hline $\begin{array}{l}\text { What are the differences between IT } \\
\text { experts and their counterpart business } \\
\text { groups which results to different } \\
\text { approaches in delivering IT services? }\end{array}$ & $\begin{array}{l}\text { The mean difference in perceptions of IT effectiveness between the IT providers and IT users is } 0.710 \text { with } \\
\text { significance }(\mathrm{t}=1.979 \text { and } \mathrm{p}=0.014) \text {. } \\
\text { The mean difference in corporate culture between the IT providers and IT users is } 1.029 \text { with significance } \\
(\mathrm{t}=2.179 \text { and } \mathrm{p}=0.008) \text {. } \\
\text { The mean difference in organizational architecture between the IT providers and IT users is } 0.511 \text { with } \\
\text { significance }(\mathrm{t}=2.179 \text { and } \mathrm{p}=0.034) \text {. } \\
\text { The overall IT effectiveness also displays a significant mean difference of } 0.681 \text { with }(\mathrm{t}=1.715 \text { and } \mathrm{p}=0.026) \text {. }\end{array}$ \\
\hline $\begin{array}{l}\text { How does corporate culture framework } \\
\text { mitigate the perceptual and cultural } \\
\text { differences between the IT users IT } \\
\text { providers? }\end{array}$ & $\begin{array}{l}\text { There is a moderate correlation between corporate culture and IT effectiveness }(\mathrm{r}=0.586) \text {. } \\
\text { The corporate culture framework significantly mitigates the perceptual and cultural differences between the IT } \\
\text { users and IT the providers }(\mathrm{F}=21.541 \text { and } \mathrm{p}<0.001) \text {. }\end{array}$ \\
\hline $\begin{array}{l}\text { How will IT experts and their business } \\
\text { group counterpart's organizational } \\
\text { architecture framework ameliorate the } \\
\text { perceptual and cultural differences } \\
\text { between IT users and IT providers? }\end{array}$ & $\begin{array}{l}\text { There is a strong positive correlation between organizational architecture and IT effectiveness }(\mathrm{r}=0.728) \text {. } \\
\text { Organizational architecture framework ameliorates the perceptual and cultural differences between the IT } \\
\text { service users and the IT providers. ( } \mathrm{F}=55.128 \text { and } \mathrm{p}<0.001) \text {. }\end{array}$ \\
\hline $\begin{array}{l}\text { How will IT effectiveness framework } \\
\text { help in the reduction of the perceptual } \\
\text { and cultural differences between the IT } \\
\text { users and IT providers? }\end{array}$ & $\begin{array}{l}\text { The socioeconomic status of an IT stakeholder increases the IT effectiveness by } 0.560(\beta=0.560 \text { and } p=0.013) \text {. } \\
\text { The increase in age of IT stakeholder increases the IT effectiveness by } 1.049(\beta=1.049 \text { and } p-v a l u e=0.002) \text {. } \\
\text { The level of education of an IT user and provider increases the IT effectiveness by } 0.641(\beta=0.641 \text { and } \\
p=0.001) \text {. } \\
\text { The organizational architecture of IT industry increases the IT effectiveness by } 1.210(\beta=1.210 \text { and } p<0.001) \text {. } \\
\text { The corporate culture of an IT industry increases the IT effectiveness by } 0.889(\beta=0.889 \text { and } p<0.001) \text {. }\end{array}$ \\
\hline
\end{tabular}




\section{Conclusion}

Both demographic factors and IT industry variables significantly affected the IT effectiveness in organizations. Information gathered through the quantitative instruments helped refine the definition of IT services per participants. Most respondents viewed IT services as operational and believed that the operational aspects of the business and IT were indistinguishable. This aligns with experts in this [9]. The demographic factors that affected the IT effectiveness were age, education level, and socioeconomic status. It was however noted that a difference in age more significantly influenced the IT effectiveness than did differences in socioeconomic status or level of education. The study shows that a positive difference in age of IT stakeholder by 1.0 increases the IT effectiveness by 1.049 times. It is also worth noting that, for every extra level of education of an IT user and provider, the IT effectiveness will increase by 0.641 . Lastly, the research found that one higher socioeconomic level of an IT stakeholder increases the IT effectiveness by 0.560 .

The study also shows that when the organizational architecture framework of an IT industry is greater by one, the IT effectiveness is greater by 1.210 . Therefore, it can be concluded that the more effective the organizational architecture in an IT industry, the higher the IT effectiveness and vice versa. It is also concluded that organizational architecture is critical to the effectiveness of the IT department and the perception of IT professionals in the minds of business professionals [2].

Similarly, when the corporate culture of an IT industry is greater by one, the IT effectiveness is greater by 0.889 . Therefore, the better the corporate culture in an IT industry, the higher the IT effectiveness and vice versa. This justifies how respondents in this study noted that the role of the IT department was to support the business. Almost unanimously the respondents envisioned a unidirectional flow in the relationship with business professionals directing problems towards the IT department [2].

Lastly, the research found that IT effectiveness can be explained using the Valued Organizational Model (VOM) of a multiple regression. The IT effectiveness was modeled from IT users' and IT providers' demographic factors and IT industry variables. Respondents agreed that it was very "important to involve IT professionals early in any business decision as IT professionals often brought value to the discovery process". The following VOM was fitted from the research data.

Where; ITE is IT Effectiveness, SES is Socioeconomic Status, EL is Education Level, OA is Organizational Architecture, $\mathrm{CC}$ is Corporate Culture, and $c$ is a constant

\section{Recommendations}

For improved IT effectiveness that will reduce perceptual and cultural differences between the IT users and IT providers, the research recommends the following:

(a) The IT stakeholders should embrace the fact that age, education level, and socioeconomic status are demographic factors that influence IT effectiveness in its relationship with business professionals. While IT professionals valued the close relationship with business professionals, they also reiterated the need to retain the integrity of the legacy application systems. IT professionals were adamant about preserving the integrity, which included code and information, of the organization's most valuable asset. This relates back to the research question on how to reduce perceptual and cultural differences. The researcher believes that age, education level, and socioeconomic status are demographic factors that influence IT effectiveness in its relationship with business professionals with a desire for a "centralized IT structure".

(b) The study also recommends that IT administrators should develop appropriate policies to improve the organizational architecture and the corporate culture to improve IT effectiveness and reduce perceptual and cultural differences as IT effectiveness is a largely subjective measure based on the believe by respondents on operational actions of IT providers.

The study also shows a positive relationship between business group and IT professionals with differential perceptions and cultural gaps. This relationship can be reliably quantified using a valued organizational model. Many business professionals in this study acknowledged that information stored in databases was critical their success and that was directly related their view of IT effectiveness [2]. To justify basis for this study's recommendation, another researcher [9], refers to this as "information literacy versus technology literacy". Experts on defining IT value stress the importance of information rather than technology as a measure of IT effectiveness [10]. Results of this study are expected to help researchers and practitioners gain additional insights into the relationships between business professionals (users) and IT providers. The study also shows that IT has evolved from an essential factor in business to a factor that will determine the fate of an organization [11]. The study ultimately provides a framework for determining the IT effectiveness within business set-up and the alignment between providers of IT services and the strategic goals IT service users.

\section{References}

[1] J. Jiang, G. Klein, C. Slyke \& P. Cheney, "A note on interpersonal and communication skills for IT professionals: Evidence of positive influence," Decision Sciences, vol. 34, no. 4, 2003, pp. 799-812.

[2] A. C. McAdams, "An investigation of the relationships between users and providers of information technology services for improved IT effectiveness," Int. J. Knowledge, Culture \& Change Management, vol. 9, no. 1, 2009, pp. 1-9. 
[3] R. Volti, "Society and technological change (3rd ed.)," New York, St. Martin's Press, 2004.

[4] A. Cooper, "The inmates are running the Asylum. Indianapolis," IN, Sams Publishing, 2004.

[5] R. Adebiaye, "Perspectives for cyber-deterrence: A quantitative analysis of cyber threats and attacks on consumers.” Int. J. Innovative Res. Sci. Eng. Technol, vol. 5, no. 7, pp. 1-17, 2016.

[6] C. R. Kothari, "Research methodology: Methods and techniques,” New Age Int., 2004.

[7] R. A. Krueger \& M. A. Casey, "Focus groups: A practical guide for applied research," Sage publications, 2014.

[8] S. A. McLeod, "Qualitative quantitative," 2008, Available: www.simplypsychology.org/qualitative-quantitative.html. [Accessed: 10 April, 2017].
[9] P. F. Drucker, "The coming of the new organization," 2014 Available: https://hbr.org/1988/01/the-coming-of-the-neworganization. [Accessed: 10 April, 2017].

[10] B. Dearstyne, "The information enterprise: New challenges new dimensions" Information Management J., vol. 39, no. 4, pp. 38-45, 2005.

[11] M. Earl \& B. Khan, "E-commerce is changing the face of IT." MIT Sloan Management Review, vol 43, no. 1, pp. 64-71, 2001.

[12] F. Ricciardi, A. Zardini \& C. Rossignoli, "The organizational integration of the IT function: A key enabler of firm capabilities and performance," J. Innovation \& Knowledge, vol.5, no. 3, 2017.

[13] R. R. Wilcox, "Introduction to robust estimation and testing," Academic Press, San Diego, CA, 2005. 